\title{
Endophenotypic markers of bipolar disorder (BD) in probands and their first degree relatives with major depression (MD)
}

Anastasia Tessa Christodoulou

From $1^{\text {st }}$ International Congress on Neurobiology and Clinical Psychopharmacology and European

Psychiatric Association Conference on Treatment Guidance

Thessaloniki, Greece. 19-22 November 2009

\section{Background}

The aim was to investigate the cognitive profile among $\mathrm{BD}$ patients and their MD first degree relatives compared to controls.

\section{Materials and methods}

Participants were 48 BD, 21 BDMD and 70 controls. All participants underwent assessment of Full Scale IQ (WAIS-R), working memory (N-back), initiation and inhibition (HSCT), cognitive set shifting and mental flexibility (WCST), memory (WMS-III), decision making and judgement (IGT), sustained attention (CPT) and interference (SCWT). Confirmation of diagnosis was made using Structured Clinical Interview for DSM-IV (SCID-I/II) and symptomatology was assessed with the HDRS and YMRS.

\section{Results}

No difference was found in IQ and initiation times 1 and 2 (HSCT). Deficits were found for both BD patients and their MDBD compared to controls in inhibitory control. In the WCST controls achieved more categories compared to both BD and BDMD in addition to perseverative errors for the former but not the later group. In terms of CPT no difference was found among the 3 groups. Working memory (N-back) was impaired in $\mathrm{BD}$ but BDMD compared to controls. Decision making (IGT) was impaired in both BD and BDMD. BD patients underperformed in the SCWT. Finally, BD were impaired on all aspects of memory (WMS-III) whereas BDMD shared deficits with their probands in visual

Department of Psychological Medicine, Institute of Psychiatry, King's College London, UK immediate and delayed memory, auditory delayed and recognition.

\section{Conclusions}

Response inhibition may be associated with genetic predisposition to $\mathrm{BD}$, irrespective of phenotype. Abnormalities in auditory and visual delayed memory and recognition in addition to decision making and judgement may relate to disease expression, irrespective of specific diagnosis.

Published: 22 April 2010

\section{References}

1. Arts B, Jabben N, Krabbendam L, van Os J: Meta-analyses of cognitive functioning in euthymic bipolar patients and their first-degree relatives. Psychol Med 2007, 9:1-15.

2. Robinson LJ, Thompson JM, Gallagher $P$, Goswami $U$, Young $A H$, Ferrier IN, Moore PB: A meta-analysis of cognitive deficits in euthymic patients with bipolar disorder. J Affect Disord 2006, 93:105-15.

doi:10.1186/1744-859X-9-S1-S90

Cite this article as: Christodoulou: Endophenotypic markers of bipolar disorder $(\mathrm{BD})$ in probands and their first degree relatives with major depression (MD). Annals of General Psychiatry 2010 9(Suppl 1):S90.

Submit your next manuscript to BioMed Central and take full advantage of:

- Convenient online submission

- Thorough peer review

- No space constraints or color figure charges

- Immediate publication on acceptance

- Inclusion in PubMed, CAS, Scopus and Google Scholar

- Research which is freely available for redistribution 